\title{
Feature extraction of Japanese spa resort hotel by Chinese students
}

Takashi Oyabu (Kokusai Business Gakuin College, oyabu24@gmail.com)

Yusuke Kajiwara (College of Information Science and Engineering, Ritsumeikan University, kajiwara@de.is.ritsumei.ac.jp)

Hiromi Ban (Graduate School of Engineering, Nagaoka University of Technology, ban@vos.nagaokaut.ac.jp)

Haruhiko Kimura (Graduate school of Natural Science and Technology, Kanazawa University, kimura@ec.t.kanazawa-u.ac.jp)

\begin{abstract}
The number of visitors from Asian countries decreased sharply due to The Great East Japan Earthquake and the trouble on Senkakus (Diaoyu Islands) in 2012. So Japan's tourism industry encountered critical situation. It is required to develop the intrinsic Japanese attractive things and commercialize them to resolve the damage. One of them is "omotenashi" (traditional Japanese hospitality) which is based on Japanese culture. It is a software technique. It is thought that the one should be exported as Japanese indigenous software and become a marketable product which can be proud to show the people of the world. It is not unique strategy to increase the number of foreign visitors. It is necessary to preserve the omotenashi and treat nicely foreign visitors through omotenashi. The export of the software is also an important one. The lodging experience in Japanese resort hotel by Chinese students was carried out to investigate the possibilities for the acceptance of omotenashi and perform an initial evaluation. As for the results, it is ranked high on facility, food and employee attitude, and it is found for Chinese to accept Japanese omotenashi even in China. However, there is some dissatisfaction in the taste of Japanese food. Omotenashi is based on the considerate behavior in the institution.
\end{abstract}

\section{Keywords}

cultural exchange, cuisine culture, cool Japan, resort hotel, Chinese visitors

\section{Introduction}

Many European and American styled hotels have been opening in Japan [Doi, 2009]. There are various types in the hotel category, for example buget, city and resort hotels [Nakamura, 2012]. The hotel business is stipulated by the Hotel Business Act in Japan and it has private typed accommodation units which have beds [Kato, 2012]. Recently, the spa resort hotels and spring inns have been increasingly used than before under the current severe economic situation, because persons are seeking healing and refreshment. Many types of European and American systems are introduced in Japanese lifestyles, and many foreign visitors are staying in the Japanese inn and spa resort hotel. Foreign people are also attracted to hot spring as a Japanese culture and it is well-known to many foreigners. Especially, spa resort hotel which is combined hot spring and the function of resort hotel is increasingly used [Oyabu and Nakajima, 2011]. It is difficult to distinguish clearly spa resort hotel and Japanese spring inn. Both facilities usually have pool-bath due to natural hot spring welling up from below. Various types of spa resort hotels are built and the ones are becoming the core in the local revitalization. There is a highquality personalized service (hospitality, omotenashi) as a feature of Japanese hotel.

The omotenashi for visitors is highly esteemed in the world and it is a distinctive service with the ones of other countries. Foreign tourists feel attracted to the omotenashi which is the typical service software. There is the high potential that the omotenashi is exported as a software business in years to come. The spa resort hotel has many stayers who seek healing and recreation. It makes an extensive contribution to the regional economy. And that is, it is required to establish the differentiated service due to omotenashi and the communitybased products. Resort hotel is profoundly affected by economic conditions and the seasons compared with budget hotel industry. There are, however many good functions for health enhancement, convalescence from fatigue and refreshment. The stayers in the hotel frequently buy souvenirs and attend an event hosted by the community, so the great economic effect is expected.

The majority of foreign tourists to Japan are from Asia [Japan Tourism Agency, 2012]. The growth rate of Chinese visitors is particularly prominent except for the decline due to the Great Japan Earthquake and the issues of the Senkakus [Yomiuri Shinbun, 2013]. Political issues have impact immediately on tourism exchange, for example Chinese visitors decreased sharply after Japan's government nationalized the Senkaku Islands in September 2012 [Chunichi Shimbun Hokuriku, 2013]. It is the challenge to establish tourism exchange which are not affected by a political issue [Oyabu, 2010]. Especially, it is necessary to understand with one another by the exchange based on culture experience.

In this study, the research is carried out to examine how Chinese student feels Japanese spa resort hotel. It is conducted through the actual experience of staying at a hotel and the study aims at exploring the possibilities whether omotenashi system could be exported to China or not in future. The results have a high significance from the view points of revitalization of tourism industry. 


\section{Questionnaire survey}

The questionnaire research was carried out through a real staying at typical Japanese spa resort hotel. The hotel name is "Hotel Arrowle" (Shibayama, Kaga City, Ishikawa, 9220402 Japan). Kaga City is in population decline [Oyabu et al., 2015]. The experiencing participants are Chinese students (two males and thirteen females) who are attending two colleges in Kanazawa City. It is one night stay with two meals (HB: half board) and held on Dec. 21-22, 2012. The staying room is twin-bedded room basically. The orientation session was held before the experience of the hotel-staying and the aim of this survey was explained. The photograph of orientation is shown in Figure 1. Hotel Arrowle has 130 guest rooms and the capacity is 280 persons. The hotel is engaged in many tourism-resource utilizations, for example traditional culture and craft arts in the region. It also organizes various events, e.g. offering a dish of natural duck which is hunted by the traditional ducking (called "Saka-ami ryo"). The hotel has good spa facility and locates close to Kanazawa City (population of 460,000). It earns high customer satisfaction through these events.

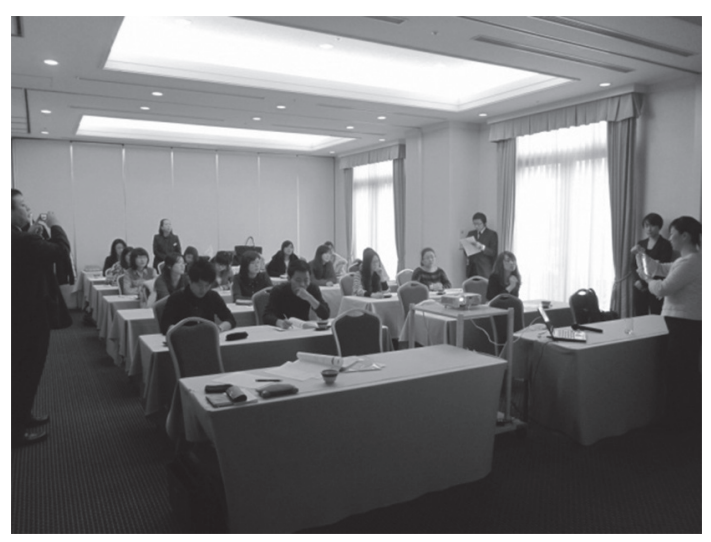

Figure 1: Photograph at the orientation

\section{Survey results}

The participants of the experience give a good evaluation on the experiencing circumstance and some participants are used to staying in Japanese hotel. They are, however, somewhat dissatisfied with individual dishes of "kaiseki ryori" (a Japanese traditional set menu of selected and handmade dishes) in the hearing investigation. The set menu is special dinner and many Japanese like the dishes. The female accounts for $87 \%$ of participants (thirteen of the fifteen participants). It is considered that the evaluation of female is very important in this investigation.

\subsection{Age distribution and lodging experience}

The age distribution of participants is within 21 to 25 years old. The average is 22.8 years and the distribution is indicated in Figure 2. One person is 21 and one is 25 years respectively. Two males are 23 and 24 years. There are many

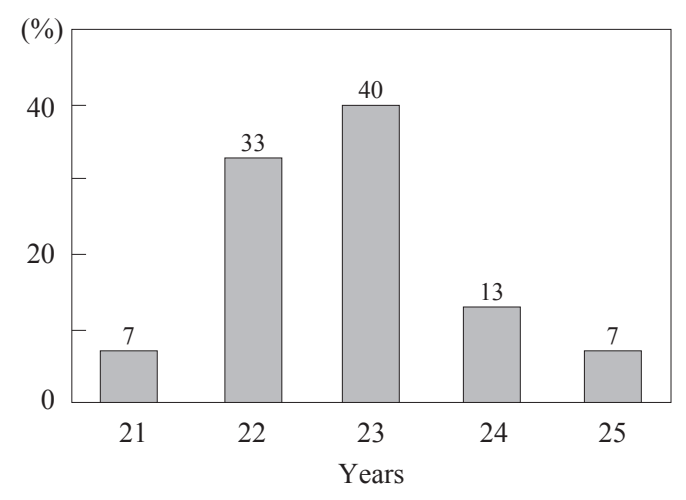

Figure 2: Age distribution of subjective person

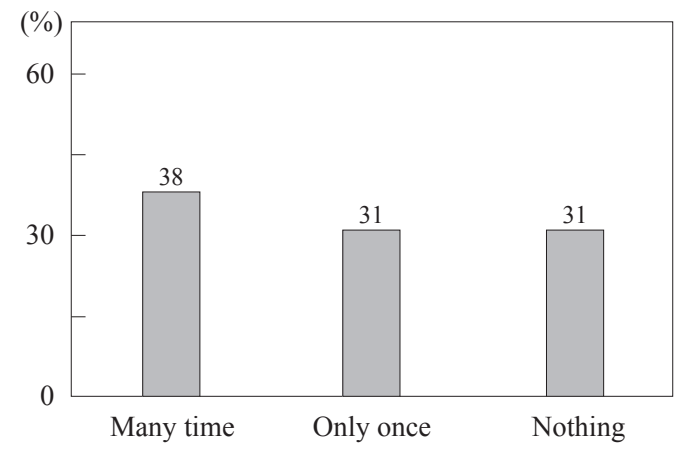

Figure 3: Frequency of hotel-accommodations

opinions from the participants and 22 to 23 years makes up the majority. Japanese hotel-accommodation frequency of the participants is shown in Figure 3. Some participants have experiences with hotel staying in Japan. There are two nonrespondents and they are not included in the figure. Multiple staying accounts for $38 \%$ and the percentage for once and new one account for $31 \%$ respectively.

\subsection{Evaluation of accommodation}

Good feelings on accommodation are got by the participants (subjects). The result is shown in Figure 4. The hotel is relatively high ranking. However, the subjects who reply "moderate" are in majority. The evaluation on the facility is

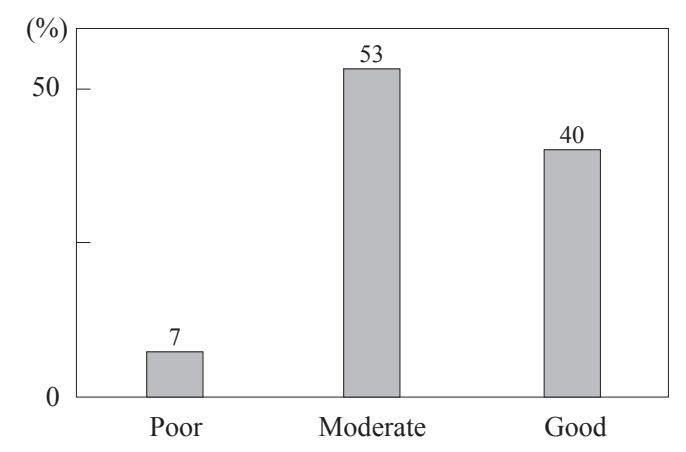

Figure 4: Feeling for accommodation 


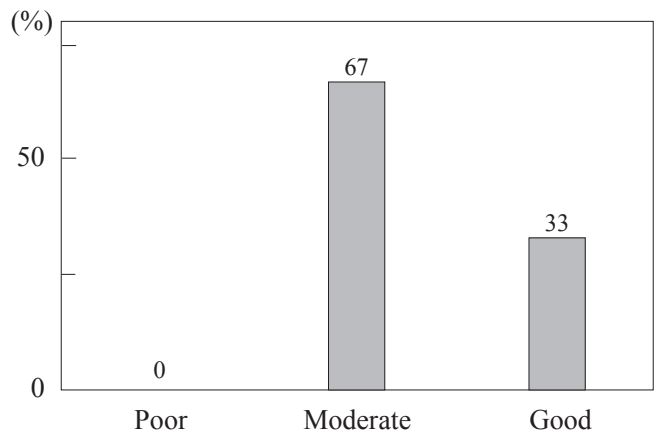

Figure 5: Evaluation for the facility

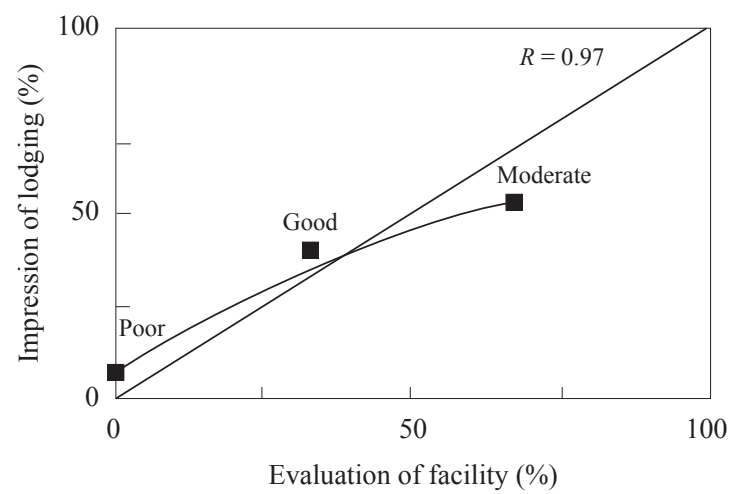

Figure 6: Relationship between impression of lodging and the evaluation of facility

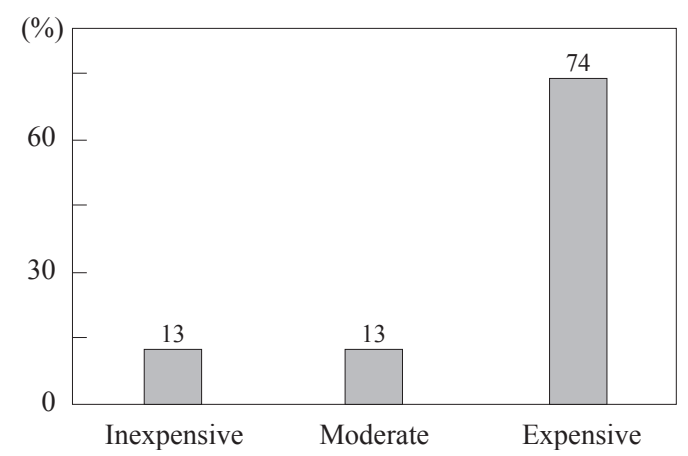

Figure 7: Price of accommodation

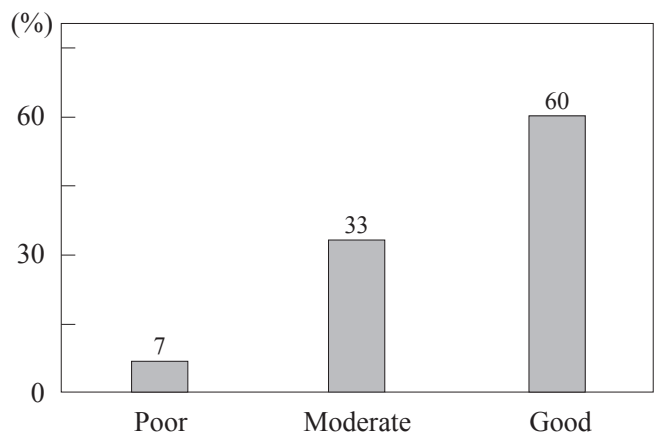

Figure 8: Evaluation for the employees exhibited in Figure 5. In the figure, the "moderate" accounts for $67 \%$ as in the case in Figure 4. Western-style hotels in China are usually gorgeous and wealthy class stays at the hotel. The accommodation charges are high. Scatter diagram is derived from Figure 4 and 5, and it is shown in Figure 6. There is a tendency to decrease the percentage of "moderate" to the impressions on the lodging than the one for the facility in the figure. Namely, the characteristic has a saturating trend in the percentage of "moderate". The correlation coefficient $r$ is 0.97 . The evaluation for the lodging is very influenced by the facility. The fee for the experience is 8,500 Yen (about 650 Yuan and 90 US dollar) per person in this stay, namely twoday and one-night staying with two meals. It costs 12,000 Yen under normal conditions. The subjects evaluated the coast as very high price. This type of hotel is popular among Chinese but they have an image of the hotel as high charges. The image for the charge is indicated in Figure 7. The evaluation for the accommodation charges is usually influenced by the behavior of the employee. Most people get a feeling that the charge is low when they have a kind hospitality by the employees. The evaluation results to the employees by the subjects are illustrated in Figure 8. More than $60 \%$ answered "good" but one person evaluated the employees as rank of "poor". There is an inverse correlation among Figure 7 and Figure 8. Namely many subjects evaluated the employees as "good" but evaluated that the price of accommodations was much higher. The following point can be given as a reason, namely the subjects are students.

\subsection{Meal in hotel}

Guests want to enjoy the provided meal during their stay at the resort hotel. In this experience, the dinner was a set menu of selected, handmade dishes served on a tray to each individual. The meal is called "kaiseki ryori" in Japan and breakfast was a buffet style in which Western, Japanese, Chinese dishes were provided. Buffet styled breakfast was highly praised by many experienced persons because they could eat their favorite dishes in moderation. Some elderly persons feel the buffet style as trouble because they must hand-carry the dishes and their favorite drinks. And they should be careful not to overeat. The dinner is very important for the guests, so each hotel takes

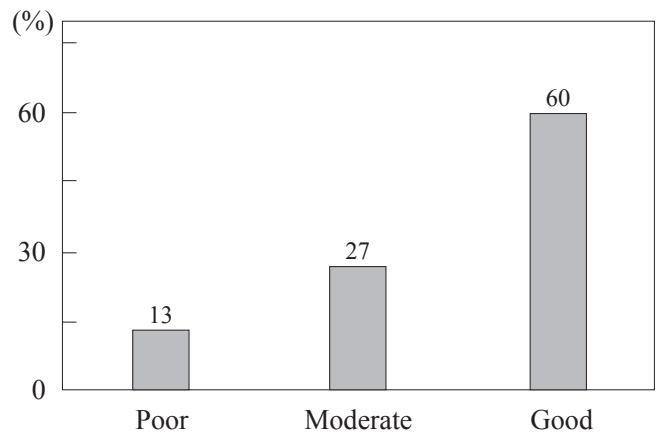

Figure 9: Evaluation for taste of kaiseki ryori 
Table 1: Score for each dish of offered kaiseki ryori

\begin{tabular}{ccc}
\hline No. & Dish & Score \\
\hline 1 & Appetizer & 3.80 \\
\hline 2 & Sashimi & 3.73 \\
\hline 3 & Hot pot & 3.53 \\
\hline 4 & Steamed fish & 3.00 \\
\hline 5 & Fried dish & 3.73 \\
\hline 6 & Vinegared food & 3.65 \\
\hline 7 & Rice and soup & 3.66 \\
\hline 8 & Dessert & 4.13 \\
\hline
\end{tabular}

Notes: Small appetizer (pink shrimp in rice malt, brown algae, kelp food), sashimi (four different fishes), hot pot (minced true sardine, chicken meat), steamed fish (seafood), fried dish (deep-fried mackerel with board laver and bun with bean-jam filling), vinegared food (crab), rice and miso soup (with pickled vegetables), dessert (pudding).

various measures to provide the gratifications for guests. The evaluation results for the dinner (kaiseki ryori) are exhibited in Figure 9. The thirteen percent of the experienced persons responds as "bad" and "good" accounts for $60 \%$. Favorite impression was made and it is thought that Japanese dishes could be accepted by Chinese. But many experienced persons are accustomed to eat Japanese meals because they are foreign students more than a year in Japan. There are following opinions, for example providing strongly flavored dishes and hot food. Many Chinese dishes are strongly-flavored and hot food. It is necessary to examine whether Japanese dishes can be accepted or not by Chinese who have never visited Japan. Japanese culture should be promoted with preserving traditional food culture and it will create Japanese cuisine boom in the world. It is an important matter.

Kaiseki ryori was served in this experience and each dish was evaluated in five ranks (5: very good, 4: good, 3: moderate, 2: poor, 1: fairly poor). The menu of kaiseki ryori is shown in Table 1. The following evaluations are carried out using a score (maximum is 5) which is derived to multiply the rank by the percentage. The results are represented in Table 1 . The dessert keeps high score, namely 4.13 because it is evaluated by young people. They like to eat dessert mostly. Small appetizer (3.8), sashimi (sliced raw fish) (3.73) and a fry (3.73) are also high score. It is a characteristic feature that the sashimi has a high score. Scores for serving pattern of dishes and the quantity are also high by the hearing invenstigation.

\subsection{Improvements presented by experienced persons}

The improvements in Hotel Arrowle which were presented by the experienced persons, were examined in this survey. And the possibility for establishing the market of the hotel into China was also investigated. At first the reply for "accept the facility in China" reaches 87 per cent and there is not "disapprove" in the replies. The result is put up in Figure 10. There is a high possibility that Japanese resort hotel can establish the market in China. However there is a room for improvement because some persons have grievances against the cost of accommodation and the facility function. The additional functions which they want in resort hotel was examined. The result is shown in Figure 11 using ABC analysis. Top four functions (events) are as in Figure 11 and the total percentage for the four events exceeds $80 \%$ (item A and B). The cumulative distribution is also indicated in the figure in

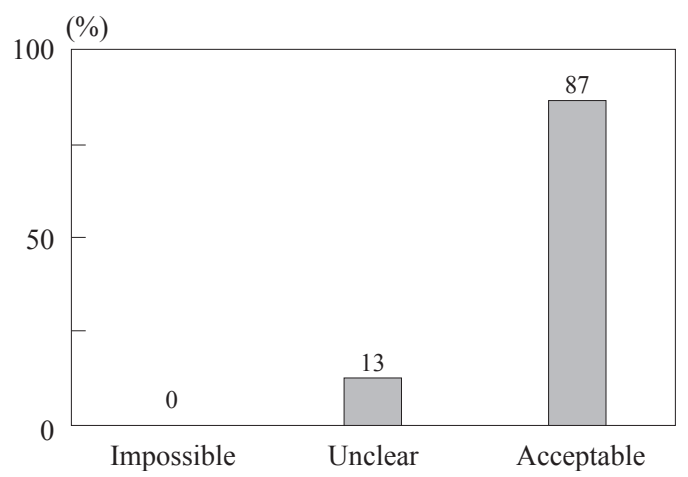

Figure 10: Possibility of spa resort hotel for expanding to China

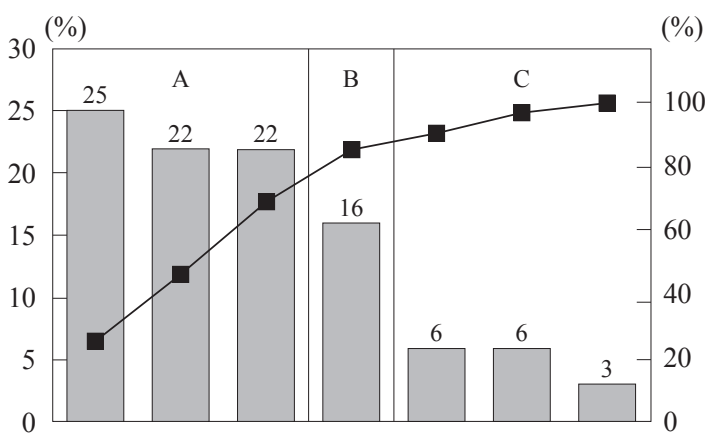

$\begin{array}{llllll}(1) & \text { (2) (3) (4) (5) (7) }\end{array}$

Figure 11: Necessary events in spa resort hotel

Notes: (1) events on Japanese culture, (2) karaoke, (3) massage \& aesthetic salon, (4) show time \& concert, (5) movie, (6) exhibition, (7) others. 


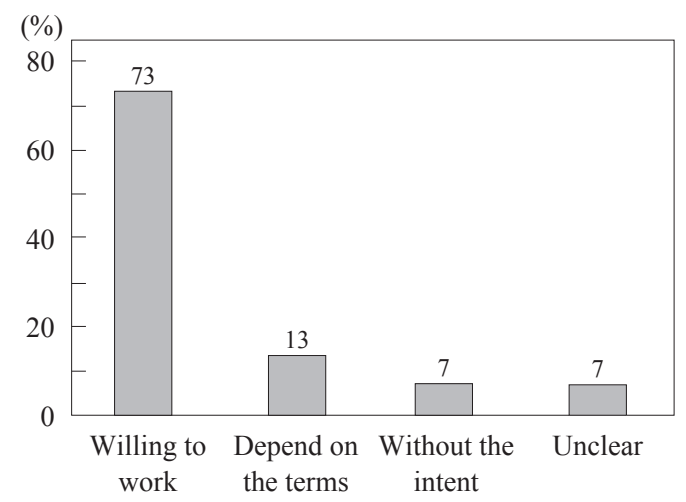

Figure 12: Desire to work in the hotel

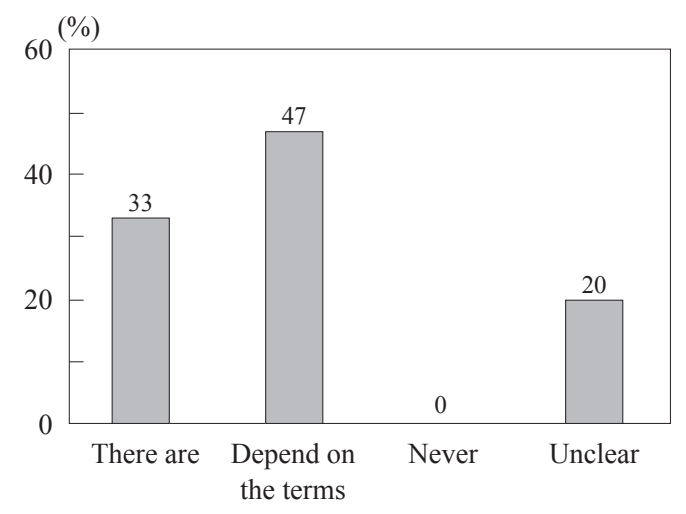

Figure 13: Possibility as worksite in China

which the items A, B and C are shown. The events will provide a greater satisfaction to the customers in the hotel. These results might be useful when Japanese hotel expands their markets to China. It is investigated whether the students have an intention to work in that kinds of hotel. The result is shown in Figure 12. The percentage who have a willing to work, accounts for $73 \%$. Possibility as a worksite in China is also examined and the result is indicated in Figure 13. There is a high possibility.

\subsection{Results of hearing investigation}

The results of hearing investigation are introduced in this section. The pros and cons are especially summarized. The item which gets the highest rating is smorgasbord breakfast (buffet). Because the experienced persons are young, and they can eat dishes they like and all they want. Other higher items are as follows, cute uniform of staff and Wi-Fi network is ready to use at all times. Meanwhile, they pointed out the following minor improvements, namely the food of hot pot was not good and there are not events. And the important assignment is that there is no plug for recharging in guest room. It is necessary for cell-phone anytime and anywhere in our time. Every hotel lays out similar souvenirs in same district and there is nothing particularly distinctive one. It is necessary to display specific souvenirs in each hotel, for example traditional crafts and packaged foods.

\section{Conclusion}

The feeling of Chinese students on Japanese resort spa hotel is examined through their staying. This survey is carried out to compile the evaluation on facility, cuisine and omotenashi in Japanese resort hotel. Japan expects that the system will be exported to China and Chinese people will visit to Japan to expose the culture. The increasing visitor number contributes to local revitalization in Japan. It arrives at a conclusion that the system is acceptable for Chinese people but some improvements are indicated, for example on food tastes and facility. It is pointed out that the additional plug in a guest room is essential to charge a cell-phone in ICT era. Most of foreign visitors use Wi-Fi facility anytime, for instance they utilize a smart phone and a handheld tablet computer in the staying hotel. The system (software) will be accepted furthermore by Chinese to mix up the following items, namely facility functions, events, cuisine and omotenashi. This experiential session in Japanese spa resort hotel was received a high evaluation by the Chinese students. However, they have a higher reputation for Japanese spa inn than the hotel, because they can experience Japanese culture in the inn. It is difficult for all foreign people to accept the Japanese culture and cuisine. It is also important topic to provide the cuisine while preserving the traditional food culture. There is no need to be fitted to Chinese culture.

\section{Acknowledgements}

This work was supported by Ministry of Economy, Trade and Industry as a strategic encouraging project in fiscal 2012 and the title is "Cool Japan Project (supporting project for overseas expansion)". Subtitle is "Business potential of Japanese inn". The authors gratefully acknowledge the support.

\section{References}

Chunichi Shimbun Hokuriku (2013). Morning edition, January $29,26$.

Doi, K. (2009). Understanding Enough for Hotel Industry. Nippon Jitsugyo Publishing.

Japan Tourism Agency (2012). White paper on tourism.

Kato, H. (2012). White Book for the Future in Tourism Business. Doyukan.

Nakamura, K. (2012). How-nual Hotel Industry Trend Guide Book. Shuwa System.

Oyabu, T. (2010). Tourism and Local Regeneration. Kaibundo.

Oyabu, T. and Nakajima, M. (2011). Tourism and the Local Revitalization. Sankeisya.

Oyabu, T., Kajiwara, Y., Ban, H. and Kimura, H. (2015). Residents' evaluation to route bus and painting show in Kaga City. Journal of Asian Electric Vehicles, Vol. 13, No. 2, 1739-1745. 
Yomiuri Shinbun (2013). Morning edition, January 26, 2.

(Received February 24, 2016; accepted April 16, 2016) 